\title{
Propriedades físico-químicas e microbiológicas do solo de um Parque em Tangará da Serra, MT, uma área de transição entre Amazônia e Cerrado
}

\author{
Eliandra Meurer MELZ1, Patricia Vieira TIAGO² \\ RESUMO \\ O Parque Natural Municipal Ilto Ferreira Coutinho, localizado em Tangará da Serra-MT, possui uma vegetação de transição \\ entre Cerrado e Floresta Amazônica e apresenta três diferentes áreas denominadas: área de lazer, área alterada e reserva natural, \\ conforme o seu estado de degradação e de utilização. Os objetivos deste trabalho foram: estudar algumas propriedades físico- \\ químicas e microbiológicas (bactérias e fungos) do solo; analisar a influência dos períodos seco e chuvoso nestas propriedades \\ do solo e estimar os índices de diversidade, uniformidade e riqueza bacteriana do solo das áreas estudadas. As amostras de \\ solo foram coletadas nos meses de agosto de 2005 e março de 2006 e as análises físico-químicas foram realizadas em um \\ laboratório especializado. As análises de $\mathrm{pH}$, umidade e contagem total de fungos e bactérias foram realizadas no Laboratório \\ de Microbiologia da UNEMAT. A diversidade bacteriana foi calculada através do índice de Shannon-Wiener e a riqueza e \\ uniformidade pelo índice de Pielou. Houveram diferenças nos valores da comunidade microbiana (fungos e actinomicetos), \\ de $\mathrm{pH}$, de matéria orgânica, de carbono orgânico e de umidade, entre as áreas e os períodos estudados. No período chuvoso, \\ observamos a inibiçáo do crescimento de actinomicetos provavelmente causado pela alta umidade. Os índices de diversidade, \\ uniformidade e riqueza foram baixos, possivelmente devido à constante ação antrópica no parque.
}

PalaVRAS-CHAVE: Bactérias, Fungos, Solo, Diversidade.

\section{Physicochemical and microbiological properties of soil in a municipal park in Tangará da Serra, MT, a transition area between Amazonia and Cerrado}

\begin{abstract}
The Ilto Ferreira Coutinho Municipal Nature Park in Tangará da Serra, state of Mato Grosso, Brazil, has a transition vegetation of "Cerrado" to Amazonian forest and encompasses three different areas classified as: leisure area, altered area, and natural reserve area, according to their state of degradation and use. The objectives of this work were to study some of the physicochemical and microbiological (bacteria and fungi) properties of the soil, analyze the influence of the dry and rainy seasons on these soil properties, and estimate the indices of bacterial diversity, homogeneity and richness in the soil of these three areas. Soil samples were collected in August 2005 and March 2006 and were subjected to physicochemical analyses in a specialized laboratory. Analyses of $\mathrm{pH}$, humidity and total fungi and bacterial counts were carried out at UNEMAT's Laboratory of Microbiology. Bacterial diversity was calculated based on the Shannon-Wiener index and bacterial richness and uniformity by the Pielou index. The microbial community (fungi and actinomycetes) and the values of $\mathrm{pH}$, organic matter, organic carbon and humidity were found to differ between areas and the dry and rainy seasons. In the rainy season, the growth of actinomycetes was inhibited, probably due to the high humidity. Diversity, homogeneity and richness indices were low, probably due to the constant anthropic action in the park.
\end{abstract}

KEYWORDS: Bacteria, Fungi, Soil, Diversity.

1Universidade do Estado de Mato Grosso. E-mail: emmelz@terra.com.br

${ }^{2}$ Universidade do Estado de Mato Grosso. E-mail: patiago@hotmail.com 


\section{INTRODUÇÃO}

A intervenção do homem em qualquer ecossistema natural causa modificaçôes que afetam o meio físico e biológico, gerando degradaçóes ao ambiente (Branco \& Cavinatto, 1999). Inevitavelmente, as transformaçôes microbianas assim como as diferentes reaçóes químicas do solo podem ser alteradas de acordo com os tipos de manejos adotados (Theodoro et al., 2003).

Embora as propriedades químicas e físicas do solo e seus efeitos no crescimento das plantas sejam intensamente investigados, as determinaçóes da biomassa microbiana e a atividade de microrganismos no solo apresentam um problema analítico complexo de avaliação (Frighetto \& Schneider, 2000). Estudos apontam para a necessidade de investigaçáo das interaçôes dos microorganismos nos processos ecológicos do solo, pois elas sofrem fortes influências decorrentes das alteraçôes do $\mathrm{pH}$, da umidade, da aeração, da temperatura e da disponibilidade de nutrientes orgânicos e inorgânicos e pelo efeito isolado ou somatório de dois ou mais fatores (Pereira $e t$ al., 2000). Os efeitos destas perturbaçóes nas propriedades do solo e na comunidade microbiana interferem na capacidade de regeneração da floresta ou mesmo na introduçáo de outras plantas (Moreira \& Costa, 2004).

No centro de Tangará da Serra está localizado o Parque Natural Ilto Ferreira Coutinho que possui uma vegetação de transição para a Floresta Amazônica (Moura, 2002) e possui três diferentes áreas denominadas área de lazer, área alterada e reserva natural, conforme seu estado de degradação e de utilização (Fundação Estadual do Meio Ambiente, 2002).

Os objetivos deste trabalho foram estudar algumas propriedades físico-químicas e microbiológicas (bactérias e fungos) do solo; analisar a influência dos períodos seco e chuvoso nestas propriedades do solo e estimar os índices de diversidade, uniformidade e riqueza bacteriana do solo das áreas de lazer, alterada e reserva natural.

\section{MATERIAL E MÉTODOS}

O estudo foi conduzido no Parque Natural Municipal Ilto Ferreira Coutinho, localizado no município de Tangará da Serra, na região Sudoeste de Mato Grosso. O Parque possui um total de 11,77 ha e apresenta três diferentes áreas: a área de lazer, onde existem brinquedos para as crianças; área alterada, local onde houve intensa movimentação de terra, construçáo de campos de futebol, construçôes de saneamento do Parque e drenagem do córrego; e a reserva natural, área que sofreu menor interferência do homem.

No interior do Parque, observa-se uma topografia suavemente ondulada, onde os solos são de dois tipos: Latossolo Vermelho Distrófico (Latossolo Vermelho) e Neossolos Quartzarênicos hidromórficos (Areias Quartzosas) com alto teor de matéria orgânica, formando nas nascentes solos hidromórficos, devido à característica de afloramento do lençol freático durante todo o ano (Embrapa, 2006). No mês de agosto de 2005 a precipitação no dia da coleta foi de zero e a mensal foi de $18 \mathrm{~mm}$ e no mês de março de 2006 a precipitação no dia da coleta foi de $10 \mathrm{~mm}$ e a mensal foi de 250 mm (Agência Nacional de Águas, 2006).

O delineamento experimental foi inteiramente casualizado em esquema de parcelas (parcelas = áreas) subdivididas (subparcelas = épocas), com três repetiçóes. As amostras de solo foram coletadas nas áreas de lazer, alterada e na reserva natural no dia 13 de agosto de 2005 e 13 de março de 2006. Em cada área de coleta foram delimitados três pontos de $1 \mathrm{~m}^{2}$ onde em cada um deles foram coletadas três subamostras formando uma amostra composta, com uma profundidade de $20 \mathrm{~cm}$, resultando em três amostras compostas de solo por área. As amostras foram levadas a um laboratório especializado para realização das análises de matéria orgânica e carbono orgânico. As análises de $\mathrm{pH}$, umidade e de densidade de bactérias e fungos foram realizadas no Laboratório de Microbiologia da Universidade do Estado de Mato Grosso (UNEMAT), Campus de Tangará da Serra.

A análise de $\mathrm{pH}$ das amostras de solo foi determinado em água (Monteiro \& Frighetto, 2000) e o teor de umidade foi obtido através da secagem do solo em estufa a $105^{\circ} \mathrm{C}$ até obtenção do peso constante (Pereira et al. 2000).

Para a avaliação da densidade de bactérias e fungos, $10 \mathrm{~g}$ de cada amostra de solo foi submetida à diluiçáo seriada em água destilada esterilizada, seguido de plaqueamento em Ágar Nutriente (AN), para quantificação de bactérias, e em BatataDextrose-Ágar (BDA), para quantificaçáo de fungos (Ribeiro $\&$ Soares, 2002). As amostras foram incubadas a $30^{\circ} \mathrm{C}$ por três e seis dias. Em BDA, também houve a quantificação de actinomicetos, possivelmente, por náo ser um meio seletivo e pelos actinomicetos serem metabolicamente diversos podendo utilizar várias fontes de carbono. Os resultados foram expressos em Unidades Formadoras de Colônias (UFC/g solo), conforme as normas para interpretação e contagem padrão em placa (Soares \& Maia, 1999).

O índice de diversidade de Shannon-Wiener, uniformidade de Pielou e o índice de riqueza foram calculados de acordo com Pinto-Coelho (2000). Para calcular o índice de diversidade bacteriana, as colônias foram agrupadas em morfoespécies de acordo com suas características morfológicas, como o tamanho, a forma, a elevação, as bordas, a estrutura, o brilho, a cor e o aspecto (Silva et al., 2001).

Os resultados relacionados à densidade de bactérias e fungos e as análises físico-químicas do solo foram submetidos à análise de variância e as médias comparadas pelo Teste t a $5 \%$ de probabilidade. Foi utilizado o software Assistat 7.4 Beta (Silva \& Azevedo, 2006). 


\section{RESULTADOS E DISCUSSÃO}

Náo foi observada interaçáo entre as áreas do parque e as épocas de avaliaçấo para a comunidade bacteriana. Esta foi afetada no período chuvoso, sendo que a área de reserva natural apresentou o maior número de bactérias diferindo da área de lazer (Tabela 1). Segundo Gonçalves et al. (1999) e Vargas \& Scholles (2000) áreas com presença de espécies vegetais exercem grande influência sobre os microorganismos e na quantidade de carbono devido ao acúmulo de matéria orgânica favorecendo o crescimento e atividade microbiana na camada superficial do solo. Pereira et al. (1996) encontraram populaçóes de bactérias em mata nativa variando de 38,9 a $154,9 \times 10^{4} \mathrm{UFC} / \mathrm{g}$, enquanto Della Bruna et al. (1991) encontraram maior atividade microbiana em solo sob mata nativa do que em solo sob eucalipto.

Para a comunidade fúngica, houve interaçáo significativa entre as áreas do parque e as épocas de avaliação. A densidade de fungos foi maior no período chuvoso (Tabela 1). Este aumento pode estar relacionado aos teores de umidade, visto que Moreira \& Siqueira (2002) verificaram mudanças nas populaçôes de fungos conforme os níveis de umidade do solo, demonstrando que quanto maior a umidade maior as populaçốes de fungos. No período seco, os fungos predominaram na área de reserva natural, possivelmente, devido à cobertura vegetal que proporcionou as melhores condiçóes para estes microrganismos. No período chuvoso, ocorreu predominância nas áreas alterada e lazer.

Para os actinomicetos, apesar do meio utilizado não ser específico a este grupo de microorganismos, houve interaçáo significativa entre as áreas do parque e as épocas de avaliação. No período seco, houve um crescimento considerável desse microrganismo com predominância na área de lazer (Tabela 1). Pereira (2000) observou um aumento significativo na densidade de actinomicetos no período seco, comportamento que está associado ao estresse provocado pela deficiência hídrica do solo, devido à umidade estar em torno de $7 \%$, resultante da ausência de chuvas. No período chuvoso, não foi observado crescimento deste microorganismo, possivelmente pelo

Tabela 1 - Densidade de bactérias, fungos e actinomicetos de amostras de solo de áreas do Parque Natural llto Ferreira Coutinho (Tangará da Serra-MT), nos períodos seco (agosto/2005) e chuvoso (março/2006).

\begin{tabular}{|c|c|c|c|c|c|c|}
\hline \multirow{3}{*}{$\begin{array}{l}\text { Áreas } \\
\text { /estação }\end{array}$} & \multicolumn{2}{|c|}{ Bactérias } & \multicolumn{2}{|c|}{ Fungos* } & \multicolumn{2}{|c|}{ Actinomicetos } \\
\hline & \multicolumn{2}{|c|}{ UFC $\times 10^{4} \mathrm{~g}^{-1}$ solo } & \multicolumn{2}{|c|}{ UFC $\times 10^{4} g^{-1}$ solo } & \multicolumn{2}{|c|}{ UFC $\times 10^{4} \mathrm{~g}^{-1}$ solo } \\
\hline & Seca & Chuva & Seca & Chuva & Seca & Chuva \\
\hline Reserva Natural & $88,7 \mathrm{aA}$ & $133,0 \mathrm{aA}$ & $3,5 \mathrm{aB}$ & $5,3 \mathrm{bA}$ & $5,8 \mathrm{bA}$ & $0 \mathrm{aB}$ \\
\hline Alterada & $51,4 \mathrm{aA}$ & $97,7 \mathrm{abA}$ & $2,0 \mathrm{bB}$ & 6,9 aA & $5,4 \mathrm{bA}$ & $0 \mathrm{aB}$ \\
\hline Lazer & $73,1 \mathrm{aA}$ & $75,3 \mathrm{bA}$ & $0,7 \mathrm{cB}$ & $6,4 \mathrm{aA}$ & $8,5 \mathrm{aA}$ & $0 \mathrm{aB}$ \\
\hline
\end{tabular}

* Dados transformados: raiz quadrada. Médias seguidas por letras distintas diferem entre si, pelo teste t a 5\% de probabilidade; letras minúsculas comparam as áreas dentro de cada época e letras maiúsculas comparam épocas dentro de cada área.

Tabela 2 - Propriedades físico-químicas de amostras de solo de áreas do Parque Natural llto Ferreira Coutinho (Tangará da Serra-MT), nos períodos seco (agosto/2005) e chuvoso (março/2006).

\begin{tabular}{|c|c|c|c|c|c|c|c|c|c|c|}
\hline \multirow{3}{*}{$\begin{array}{l}\text { Áreas } \\
\text { /estação }\end{array}$} & \multirow{2}{*}{\multicolumn{2}{|c|}{$\mathrm{pH}$}} & \multirow{2}{*}{\multicolumn{2}{|c|}{$\frac{\text { Matéria Orgânica }}{\mathrm{g} / \mathrm{Kg}}$}} & \multirow{2}{*}{\multicolumn{2}{|c|}{$\begin{array}{c}\text { Carbono Orgânico } \\
\mathrm{g} / \mathrm{Kg}\end{array}$}} & \multirow{2}{*}{\multicolumn{2}{|c|}{$\begin{array}{c}\text { Umidade } \\
(\%)\end{array}$}} & \multirow{2}{*}{\multicolumn{2}{|c|}{$\begin{array}{c}\text { Temperatura } \\
\left({ }^{\circ} \mathrm{C}\right)\end{array}$}} \\
\hline & & & & & & & & & & \\
\hline & Seca & Chuva & Seca & Chuva & Seca & Chuva & Seca & Chuva & Seca & Chuva \\
\hline $\begin{array}{l}\text { Reserva } \\
\text { Natural }\end{array}$ & $5,8 \mathrm{bB}$ & $6,8 \mathrm{aA}$ & 45,6 aA & $36,2 \mathrm{bB}$ & 26,5 aA & 21,04 bB & $7,8 \mathrm{aB}$ & $70 \mathrm{aA}$ & $24,1 \mathrm{aA}$ & $24,0 \mathrm{aA}$ \\
\hline Alterada & $4,8 \mathrm{cB}$ & $6,6 \mathrm{abA}$ & $16,1 \mathrm{bA}$ & $13,4 \mathrm{cA}$ & $9,4 \mathrm{bA}$ & $7,79 \mathrm{cA}$ & $7,6 \mathrm{aB}$ & $68 \mathrm{aA}$ & $24,5 \mathrm{aA}$ & 24,6 aA \\
\hline Lazer & $6,8 \mathrm{aA}$ & 6,4 bB & $12,1 \mathrm{cB}$ & 42,9 aA & $7,0 \mathrm{cB}$ & $24,94 \mathrm{aA}$ & $6,7 \mathrm{aB}$ & $62 \mathrm{bA}$ & 25,6 aA & 26,3 aA \\
\hline
\end{tabular}

Médias seguidas por letras distintas diferem entre si, pelo teste t a $5 \%$ de probabilidade; letras minúsculas comparam as áreas dentro de cada época e letras maiúsculas comparam épocas dentro de cada área. 
aumento da umidade, pois, há evidências que os actinomicetos requerem, para o seu crescimento, potencial de água menor que várias outras bactérias de solo (Madigan, 2004).

Houve interação significativa entre as áreas do parque e as épocas sobre o $\mathrm{pH}$ (Tabela 2). Os valores de $\mathrm{pH}$ do solo encontrados nas diferentes áreas e períodos favoreceram as bactérias (Tabelas 1 e 2). Conforme Siqueira et al. (1994) as bactérias, incluindo actinomicetos, são mais adaptadas a $\mathrm{pH}$ com valores entre 6 e 8 e os fungos a valores abaixo de 5 , contudo eles são menos sensíveis ao aumento do $\mathrm{pH}$ que as bactérias (Sanomiya \& Nahas, 2003).

Para os teores de matéria orgânica e carbono orgânico, foi observada interação significativa entre as áreas e as épocas (Tabela 2). No período chuvoso, foi verificada uma redução nos teores de matéria orgânica e carbono orgânico na área de reserva natural e um aumento desses compostos na área de lazer (possivelmente o valor alto verificado na área de lazer possa ser devido a algum fator pontual, pois não se esperava um valor maior nesta área). De acordo com Marchiori Júnior \& Melo (2000) a redução do aporte de matéria orgânica e carbono orgânico no solo está relacionada à quantidade de resíduos adicionados através da deposição de serrapilheira e ao aumento da atividade microbiana visto que utilizam estes componentes orgânicos para suprir suas necessidades metabólicas. Segundo Resck et al. (1991) as flutuaçôes na precipitaçâo entre os períodos de seca e chuva não influenciaram na quantidade e permanência de matéria orgânica e carbono orgânico no solo. No período seco, a área de reserva natural apresentou maior quantidade de matéria orgânica e carbono orgânico, enquanto no período chuvoso o mesmo ocorreu para a área de lazer.

Houve interação significativa entre as áreas e as épocas sobre a umidade. Nas três áreas estudadas, foi observado um aumento significativo da umidade no período chuvoso, devido à diferença na precipitação pluviométrica ocorrida nos períodos de coleta das amostras. No período chuvoso, a área de reserva natural e área alterada apresentaram os maiores teores de umidade (Tabela 2).

Não houve interação significativa entre as áreas e as épocas sobre a temperatura (Tabela 2). Assis Júnior et al. (2003) observaram que a precipitação afeta diretamente a umidade e a temperatura do solo, as quais têm influência na atividade da microbiota e verificaram relaçôes lineares entre o potencial de água no solo e sua atividade biológica. As temperaturas observadas no solo das diferentes áreas estudadas são favoráveis a microorganismos mesófilos que possuem uma faixa de crescimento entre $25^{\circ} \mathrm{C}$ e $40^{\circ} \mathrm{C}$ (Tsai \& Rossetto, 1992). Moreira \& Siqueira (2002) observaram que as variaçóes sazonais de temperatura e umidade afetam as comunidades biológicas do solo e suas atividades devido a condiçôes adversas para seu desenvolvimento.

Foram observadas 59 morfoespécies de bactérias no período seco e 31 morfoespécies no período chuvoso. No período seco, a área de reserva natural apresentou maior número de morfoespécies, enquanto no período chuvoso, foi a área alterada que apresentou o maior número (Tabela 3). A diversidade de bactérias pode estar relacionada ao uso do local, visto que as áreas de reserva natural e alterada sofrem menor ação antrópica.

Os índices de diversidade e uniformidade foram baixos. O baixo índice de uniformidade está relacionado com a distribuição das colônias de bactérias nas amostras de solo, visto que em certas áreas houve maior concentração de morfoespécies e que ocorreram em quantidades diferentes entre os períodos.

Foi observado o maior índice de riqueza na área de reserva natural no período seco e na área alterada no período chuvoso (Tabela 3). Apesar dos valores variarem muito dependendo da amostra estudada, o índice de diversidade de Shannon Wiener varia de 1 ao valor máximo de 5, Pielou (1966) citado por Oliveira \& Amaral (2005). De acordo com Odum (1988) em situaçóes de alta diversidade a média da uniformidade apresenta-se em torno de 80. Estes dados demonstraram que dentro das amostras estudadas houve uma baixa diversidade e uniformidade de espécie com uma maior riqueza de espécies nas áreas de reserva natural e alterada.

A área de lazer apresentou os menores índices de diversidade, uniformidade e riqueza em ambos os períodos, Com exceção do índice de riqueza no período chuvoso, possivelmente por ser uma área de constante utilização para fins recreativos. Segundo Odum (1988) a diversidade de

Tabela 3 - Total de morfoespécies, índices de diversidade, uniformidade e riqueza bacteriana de amostras de solo de áreas do Parque Natural Ilto Ferreira Coutinho (Tangará da Serra-MT), nos períodos seco (agosto/2005) e chuvoso (março/2006).

\begin{tabular}{|c|c|c|c|c|c|c|c|c|}
\hline \multirow{2}{*}{$\begin{array}{l}\text { Áreas/ } \\
\text { estação }\end{array}$} & \multicolumn{2}{|c|}{ Total de Morfoespécies } & \multicolumn{2}{|c|}{ Índice de diversidade } & \multicolumn{2}{|c|}{ Índice de uniformidade } & \multicolumn{2}{|c|}{ Índice de riqueza } \\
\hline & Seca & Chuva & Seca & Chuva & Seca & Chuva & Seca & Chuva \\
\hline Reserva natural & 27 & 7 & 2.743 & 1,09 & 0,84 & 0,61 & 25,84 & 5,80 \\
\hline Alterada & 24 & 17 & 2.856 & 2,15 & 0,90 & 0,75 & 22,79 & 16,87 \\
\hline Lazer & 8 & 7 & 1.684 & 0,99 & 0,80 & 0,50 & 7,70 & 6,85 \\
\hline
\end{tabular}


espécies tende a ser reduzida em comunidades que sofrem estresse.

\section{CONCLUSÃO}

Os períodos de seca e chuva e as áreas do parque influenciaram a comunidade de fungos e actinomicetos e as propriedades físico-químicas como $\mathrm{pH}$, matéria orgânica, carbono orgânico e umidade das amostras de solo. As bactérias foram afetadas no período chuvoso, predominando na área de reserva natural. Os fungos predominaram no período chuvoso, enquanto os actinomicetos predominaram no período seco. Estes dois fatos podem estar relacionados com o aumento significativo da umidade no período chuvoso. Os índices de diversidade, uniformidade e riqueza apresentaram valores baixos, tendo a área de lazer apresentado os menores índices de diversidade, uniformidade e riqueza, possivelmente provocados pela constante ação antrópica que o Parque sofre.

\section{BIBLIOGRAFIA CITADA}

Agência Nacional de Águas. 2006. Estação Metereológica, Tangará da Serra-MT.

Assis Júnior, S.L.; Zanuncio, J.C.; Kasuya, M.C.M.; Couto, L.; Melido, R.C.N. 2003. Atividade microbiana do solo em sistemas agroflorestais, monocultura, mata natural e área desmatada. Revista Árvore, 27(1): 35-41.

Branco, S.M.; Cavinatto, V.M. 1999. Solos: a base da vida terrestre. Moderna, São Paulo. 79pp.

Della Bruna, E.; Borges, A.C.; Fernandes, B.; Barros, N.F.; Muchovej, R.M.C. 1991. Atividade da microbiota de solos adicionados de serrapilheira de eucalipto e de nutrientes. Revista Brasileira de Ciência do Solo, 15: 15-20.

Embrapa. Centro Nacional e Pesquisa em solos. Sistema Brasileiro de Classificaçâo dos solos. Brasília: Embrapa-SPI; Rio de Janeiro: Embrapa-Solos, 2006. 306pp.

Frighetto, R.T.S.; Schneider, R.P. 2000. Problemas encontrados na avaliação de microrganismos do solo. In: Frighetto, R.T.S.; Valarini, P.J. (Coords.). Indicadores biológicos e bioquimicos da qualidade do solo: manual técnico. Embrapa Meio Ambiente, Jaguariúna. 198p. (Embrapa Meio Ambiente. Documento, 21).

Fundação Estadual Meio Ambiente. 2002. Parque Natural Municipal Ilto Ferreira Coutinho. Laudo técnico. Tangará da Serra-MT.

Gonçalves, A.S.; Monteiro, M.T.; Bezerra, F.E.A.; Guerra, J.G.M.; De-Polli, H. 1999. Estudo de Variáveis de Solo, Vegetação e Condicionamento de Amostras de Solo Sobre a Biomassa Microbiana do Solo no Estado do Rio de Janeiro. Embrapa Agrobiologia, Seropédica. 18p. (Embrapa- CNPAB. Documentos, 90).

Madigan, M.T. 2004. Microbiologia de Brock. Prentice Hall, São Paulo. 608pp.

Marchiori Júnior, M.; Melo, W.J. 2000. Alteraçôes na matéria orgânica e na biomassa microbiana em solo de mata natural submetido a diferentes manejos. Pesquisa Agropecuária Brasileira, Brasília, 35(6): 1177-1182.

Monteiro, R.T.R.; Frighetto, R.T.S. 2000. Determinação da umidade, $\mathrm{pH}$ e capacidade de retenção de água do solo. In: Frighetto, R.T.S.; Valarini, P.J. (Coords.). Indicadores biológicos e bioquímicos da qualidade do solo: manual técnico. Embrapa Meio Ambiente, Jaguariúna. 198p. (Embrapa Meio Ambiente. Documento, 21).

Moreira, F.M.S.; Siqueira, J.O. 2002. Microbiologia e bioquímica do solo. UFLA/FAEPE, Lavras. 626pp.

Moreira, A.; Costa, D.G. 2004. Dinâmica da matéria orgânica na recuperaçáo de clareiras da floresta amazônica. Pesquisa Agropecuária Brasileira, Brasília, 39(10): 1013-1019.

Moura, C.B. 2002. Projeto de recuperação de áreas degradadas-Parque Natural Ilto Ferreira Coutinho. Prefeitura Municipal de Tangará da Serra-MT.

Odum, E.P.1988. Populaçôes em comunidades. In: Odum, E.P. (Eds). Ecologia. Guanabara, São Paulo. p. 258-272.

Oliveira, A.N.; Amaral, I.L. 2005. Aspectos florísticos, fitossociológicos e ecológicos de um sub-bosque de terra firme na Amazônia Central, Amazonas, Brasil. Acta Amazonica, 35(1): 1-16.

Pereira, J.C.; Neves, M.C.P.; Drozdowicz, A.1996. Quantificaçâo das populaçóes de bactérias em geral, de bactérias resistentes a antibióticos $e$ de actinomicetos em solos. Embrapa Agrobiologia, Seropédia. 21p. (Embrapa-CNPAB. Documentos, 26).

Pereira, J.C.; Neves, M.C.P.; Gava, C.A.T. 2000. Efeito do cultivo da soja na dinâmica da populaçáo bacteriana em solos de cerrado. Pesquisa Agropecuária Brasileira, Brasília, 35 (6):1183-1190.

Pereira, J.C. 2000. Interaçôes entre as populaçōes de actinomicetos e outros organismos na rizosfera. Embrapa Agrobiologia, Seropédia. 15p. (Embrapa- CNPAD. Documentos, 118).

Pinto-Coelho, R.M. 2000. Fundamentos em Ecologia. Artmed Editora, Porto Alegre. 252pp.

Resck, D.V.S.; Pereira, J.; Silva, J.E. 1991. Dinâmica da matéria orgânica na região dos Cerrados. Embrapa-CPAC, Planaltina. 22p. (Embrapa-CPAC. Documentos, 36).

Ribeiro, M.C.; Soares, M.M.S.R. 2002. Microbiologia prática: roteiro e manual de bactérias e fungos. Atheneu, São Paulo. 112pp.

Sanomiya, L.T.; Nahas, E. 2003. Microrganismos produtores de hidrolases envolvidos nas transformaçóes dos compostos do carbono e do nitrogênio do solo. Ciência Rural, Santa Maria, 33(5): 835-842.

Silva, F.A.S.; Azevedo, C.A.V. A new version in the Assistat Statistical Assistance Software, Orlando, Florida, USA, 2001. In: Word Congresso on Computers in Agriculture, 4., 2006, Orlando, Florida, USA. Anais... Orlando, American Society of Agricultural Engineers, 2006. p.393-396.

Silva, R.; Schwan, R.F.; Dias, E.S. 2001. Aulas práticas de microbiologia geral. UFLA, Lavras. 52pp.

Siqueira, J.O.; Moreira, F.M.S; Grisi, B.M.; Hungria, M.; Araújo, R.S. 1994. Microrganismos e processos biológicos do solo: perspectiva ambiental. Embrapa, Brasília. 142p. (Embrapa, documento, 45). 
Soares, J.B.; Maia, A.C.F. 1999. Água: microbiologia e tratamento. EUFC, Fortaleza. 206pp.

Tsai, S.M.; Rossetto, R.1992. Transformações microbianas do fósforo. In: Cardoso, E.J.B.N.; Tsai, S.M.; Neves, M.C.P. Microbiologia do solo. Sociedade Brasileira de Ciências do Solo, Campinas. p. 231-242.

Theodoro, V.C.A.; Alvarenga, M.I.N.; Guimarães, R.J.; Mourão Júnior, M. 2003. Carbono da biomassa microbiana e micorriza em solo sob mata nativa e agroecossistemas cafeeiros. Acta Scientiarum: Agronomy, Maringá, 25(1): 147-153.
Vargas, L.K.; Scholles, D. 2000. Biomassa microbiana e produçáo de $\mathrm{C}-\mathrm{CO}_{2}$ e N mineral de um podzólico vermelho-escuro submetido a diferentes sistemas de manejo. Revista Brasileira de Ciência do Solo, Viçosa, 24: 35-42.

Recebido em 18/07/2008

Aceito em 30/03/2009 